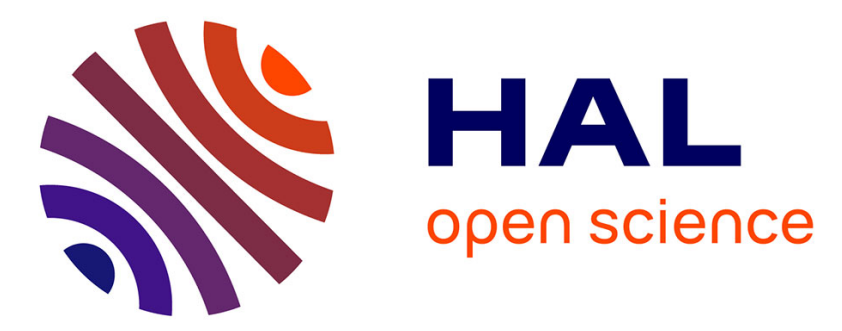

\title{
Sensitivity analysis of catenary geometry on current collection quality
}

Olivier Vo Van, Etienne Balmès, Arnaud Capitaine, Xavier Lorang

\section{To cite this version:}

Olivier Vo Van, Etienne Balmès, Arnaud Capitaine, Xavier Lorang. Sensitivity analysis of catenary geometry on current collection quality. The Third International Conference on Railway Technology: Research, Development and Maintenance, Apr 2016, Cagliari, Italy. pp.1-17. hal-01341169

\section{HAL Id: hal-01341169 \\ https://hal.science/hal-01341169}

Submitted on 4 Jul 2016

HAL is a multi-disciplinary open access archive for the deposit and dissemination of scientific research documents, whether they are published or not. The documents may come from teaching and research institutions in France or abroad, or from public or private research centers.
L'archive ouverte pluridisciplinaire HAL, est destinée au dépôt et à la diffusion de documents scientifiques de niveau recherche, publiés ou non, émanant des établissements d'enseignement et de recherche français ou étrangers, des laboratoires publics ou privés. 


\title{
Sensitivity analysis of catenary geometry on current collection quality
}

\author{
O. Vo Van ${ }^{1,2}$, E. Balmes ${ }^{2,3}$, A. Capitaine ${ }^{4}$, X. Lorang ${ }^{1}$ \\ ${ }^{1}$ SNCF, Research Department, Paris, France \\ ${ }^{2}$ Arts \& Metiers ParisTech, Paris, France \\ ${ }^{3}$ SDTools, Paris, France \\ ${ }^{4}$ SNCF Reseau, Engineering department, Saint-Denis, France \\ e-mail: olivier.vo_van@sncf.fr
}

\begin{abstract}
A global sensitivity analysis is led on catenary parameters such as dropper lengths, height of the messenger wire at masts and mechanical tensions in the wires thanks to the Sobol indices. All parameters are defined using experimental measurements. A set of geometric and dynamic criteria is selected as output and the contribution of the input parameters to the output variability is quantified. It is shown that the dynamic interaction is mainly sensitive to the mechanical tensions in contact and messenger wires whereas existing geometric criteria are mainly dependent on height of messenger wire at masts. Moreover, selected geometric criteria available using geometry measurements are hardly correlated with dynamic criteria.
\end{abstract}

Keywords: pantograph-catenary, maintenance policy, global sensitivity analysis, Sobol indices.

\section{Introduction}

Development of numerical models is a main focus of current research in pantographcatenary interaction. As shown in the benchmark led by S. Bruni [1], software modelling this interaction are becoming very accurate for a deterministic case. Simultaneously, improvements in simulation speeds and parallel computations make the use of parametric or statistical studies possible.

Thanks to the quick expansion of computation capacity, studies recently moved to optimisation or sensitivity analysis of pantograph [2,3], catenary [4] or both [5, 6]. But none of them addressed the variability as an irreducible component. An important trend of studies performed at SNCF is to introduce this variability into the input parameters of the model. A previous work [7] showed that the variability of geometry 
of the catenary is one of the most critical ones. Furthermore, maintenance policy allows variation of the contact wire height inside tolerance margins through two criteria. Although these criteria exist to prevent deterioration of current collection quality as well as for security check, these might not be appropriate to ensure a good current collection quality.

This paper proposes to lead a global sensitivity analysis on catenary parameters in order to compare their influence on geometric and dynamic criteria. Several new geometry criteria are introduced in order to find which are better correlated with dynamic criteria.

First, the choice of statistic distributions of selected input parameters is explained. Next, the list of output criteria chosen is detailed. Then, the method of Sobol analysis is developed for our case and finally results are shown.

\section{Identified input parameters}

\subsection{Description of input variability}

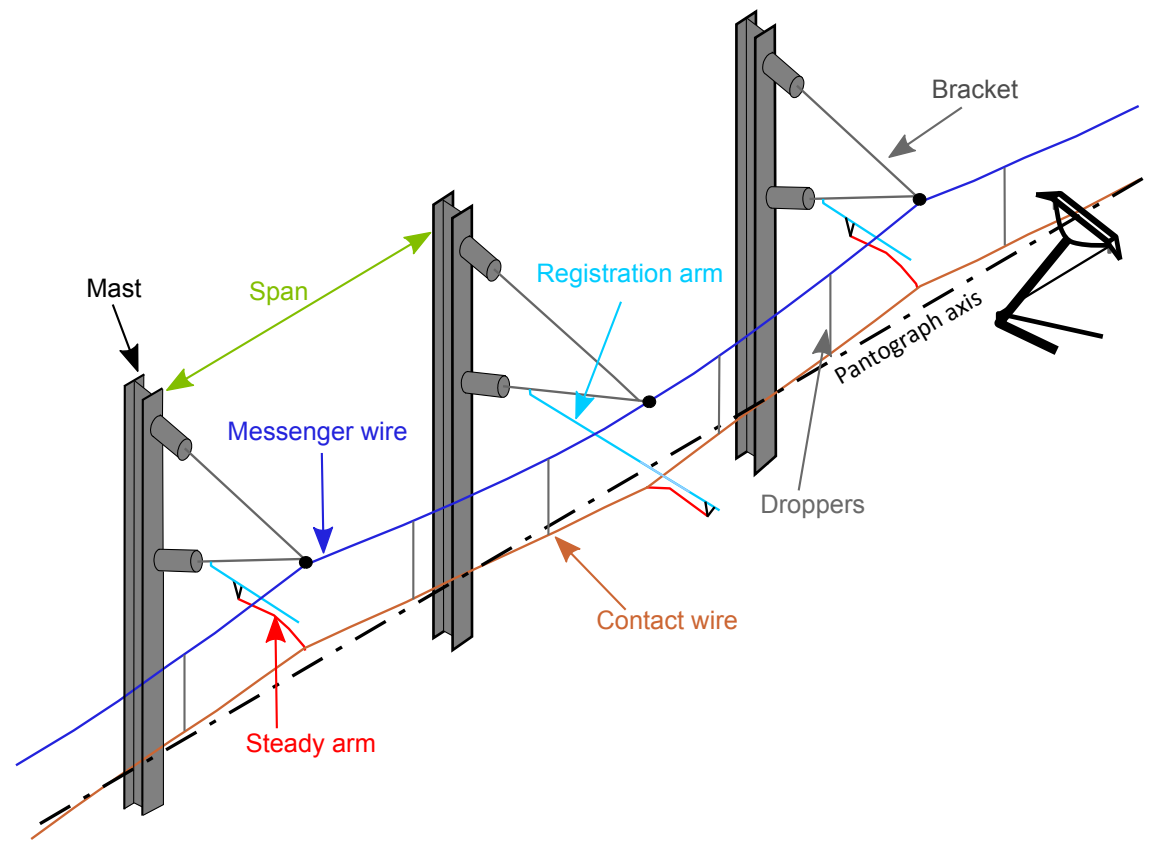

Figure 1: Components of a catenary

The catenary system used for the study is a french type catenary V350. The different components are detailed in figure 1. The finite element (FE) model used for dynamic computation is composed of bars, beams, masses and non-linear elements for droppers. The masts, brackets and registration arms are not modelled. The messenger wire 
and the end of steady arms are thus directly fixed.

Figure 2 shows the FE model on the left and a drawing of one span on the right, highlighting the different parameters of the catenary which may influence the static sag of the contact wire. A previous study [8] aimed at determining the variability of each of these parameters. Table 1 summarizes the standard deviations $\sigma$ chosen for each parameters except $\Delta H_{\text {mast }}$ (left and right) which will be discussed later. For the sake of simplicity, all parameter distributions are Gaussian and have their nominal values as mean value.

Parameters like the length or angle of the steady arm have been studied separately and do not seem to impact either geometry or dynamic response for consistent variations.
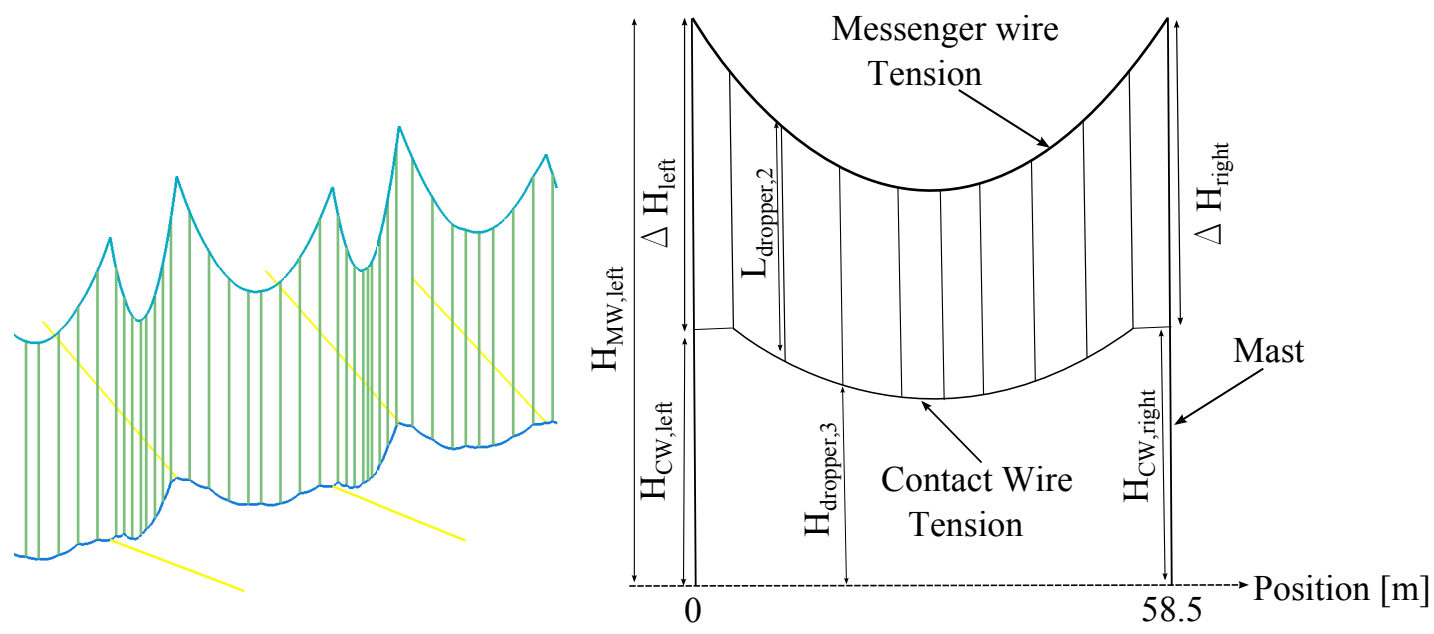

Figure 2: Catenary FE model (left) and components of one span (right)

No information is available about variability of the contact wire tension $T_{C W}$. Nevertheless, its impact on dynamic interaction is well known. That is why the assumption that its variability is the same as the one of $T_{M W}$, namely, a Gaussian variation with a standard deviation of $1000 \mathrm{~N}$, is made.

The last parameter introduced here is the heigh of the messenger wire at mast, $\boldsymbol{H}_{M W, M a s t}$. The distribution of $\boldsymbol{H}_{M W, M a s t}$ is defined from measurements of the contact wire height at mast, $\boldsymbol{H}_{\boldsymbol{C W}, \text { Mast }}$. The mean value mean $\left(\boldsymbol{H}_{M W, M a s t}\right)$ will be chosen equal to mean $\left(\boldsymbol{H}_{C W, M a s t}\right)+\Delta H_{\text {Mast }}$, with $\Delta H_{\text {Mast }}$, the nominal distance between the contact and messenger wires at masts, which might be different between spans. In the general case, $\Delta H_{\text {Mast }}=1.40 \mathrm{~m}$. The first assumption is thus that the variations of $\boldsymbol{H}_{M W, M a s t}$ are approximately the same as those of $\boldsymbol{H}_{C W, M a s t}$.

The second assumption is that $\boldsymbol{H}_{M W, \text { Mast }}$ is a Gaussian random vector of size $n_{\text {mast }}$, the number of masts in the model, mean $\boldsymbol{m}_{\boldsymbol{X}}$ and covariance $C_{\boldsymbol{X}}$.

$$
\begin{aligned}
\boldsymbol{m}_{\boldsymbol{X}} & =E\left(\boldsymbol{H}_{\boldsymbol{M W}, \text { Mast }}\right) \\
C_{\boldsymbol{X}} & =E\left\{\left(\boldsymbol{H}_{\boldsymbol{M W}, \text { Mast }}-\boldsymbol{m}_{\boldsymbol{X}}\right)\left(\boldsymbol{H}_{\boldsymbol{M W}, \text { Mast }}-\boldsymbol{m}_{\boldsymbol{X}}\right)^{T}\right\}
\end{aligned}
$$


This assumption is consistent with the maximum entropy principle [9] (see [10] for examples) applied to a random vector $\boldsymbol{H}_{M W, M a s t}$ on which the only available information are the mean value, $\boldsymbol{m}_{\boldsymbol{X}}$ and the covariance matrix $C_{\boldsymbol{X}}$.

If a singular value decomposition is applied to $C_{\boldsymbol{X}}$,

$$
C_{\boldsymbol{X}}=U \cdot \lambda \cdot U^{\prime}
$$

$\boldsymbol{H}_{M W, M a s t}$ can be written [11] as a product of the root matrix $R$ defined by

$$
R=U \cdot \lambda^{1 / 2} \cdot U^{\prime}
$$

and a normalized independent, identically distributed Gaussian vector $\boldsymbol{W}$ of size $n_{\text {mast }}$,

$$
\boldsymbol{H}_{M W, M a s t}=R \cdot \boldsymbol{W} .
$$

The covariance matrix $C_{\boldsymbol{X}}$, of size $n_{\text {mast }} * n_{\text {mast }}$ has to be defined from measurements. In that case, $n_{\text {mast }}=24$ and the number of measurements of $\boldsymbol{H}_{C W, \text { Mast }}$ at $n_{\text {mast }}$ consecutive masts is of 695 . It seems large enough but $C_{\boldsymbol{X}}$ is variable when changing the size $n_{\text {mast }}$ and covariance between spans separated of a fixed distance can change drastically. Two observations are made to solve this issue.

First, the section 2.2 shows that a modified span dynamic influence is negligible three spans further away. The covariance matrix is thus simplified by setting to zero covariances between $\boldsymbol{H}_{M W, M a s t}$ at masts separated of three spans or more. This means that even if $\boldsymbol{H}_{M W, \text { Mast }}$ at one mast is strongly dependent to $\boldsymbol{H}_{M W, \text { Mast }}$ three masts after or before, this covariance is not taken into account.

The second observation is that the function $C_{\boldsymbol{X}}$ can be approximated to a stationary estimator as explained by Perrin [12]. In practice, this means that inside a section, the covariance between two consecutive $\boldsymbol{H}_{M W, M a s t}$ are not dependent to their position in the section. The diagonal and super-diagonals of $C_{\boldsymbol{X}}$ are thus constant values and the matrix has the form

$$
C_{\boldsymbol{X}}=\left[\begin{array}{ccccc}
a & b & c & 0 & \cdots \\
b & a & b & c & \ddots \\
c & b & \ddots & \ddots & \ddots \\
0 & c & \ddots & \ddots & \ddots \\
\vdots & \ddots & \ddots & \ddots & \ddots
\end{array}\right]
$$

Finally, an experimental set of 2052 measurements collected by an optical system on the line called $L N 1$ between the cities of Paris and Lyon lead the $a, b$ and $c$ coefficients:

$$
a=3.88 e^{-4} \quad b=3.23 e^{-4} \quad c=3.06 e^{-4}
$$


In the previous study [8], the distance between contact wire and messenger wire at masts $\Delta H_{\text {mast }}$ was fixed, which is not the case in the full catenary model where this value is not defined and depends on other parameters. It appears that leaving $\Delta H_{\text {mast }}$ to its nominal value and letting every other parameters vary leads to a standard deviation of $\Delta H_{\text {mast }}$ of $8 \mathrm{~mm}$ which is approximately the same variability found previously. This parameter can thus be removed from the list of input parameters. Finally, all the input parameters variabilities can be summarized in the table 1.

Table 1: Input parameters variability

\begin{tabular}{c|c|c|c|c} 
Parameter & $T_{M W}$ & $T_{C W}$ & $\boldsymbol{L}_{\text {drop }}$ & $\boldsymbol{H}_{\boldsymbol{M W}, \boldsymbol{M a s t}}$ \\
\hline Distribution & Gaussian & Gaussian & Gaussian & Multivariate Gaussian \\
\hline$\sigma$ & $1000 N$ & $1000 N$ & $7 \mathrm{~mm}$ & matrix $C_{\boldsymbol{X}}$
\end{tabular}

\subsection{Impact of MW height at masts on dynamic interaction}

In order to study the dynamic influence of the messenger height on the interaction behaviour a few masts after, simulations have been carried out. A track of the French high speed overhead contact line, named V350 STI, with nominal geometry has been modelled. Besides, considering the same model, changes were applied so that heights of messenger wire at three consecutive supports are different from the nominal one. New values have been taken from an empiric observation. Simulations have been carried out at a speed of $320 \mathrm{kph}$ with two $200 \mathrm{~m}$ spaced pantographs. In order to take into account span length influence on the dynamic results, different studies have been performed considering different span lengths ( $45 \mathrm{~m}$ up to $63 \mathrm{~m}$ ).

Dynamic behaviour of the catenary-pantographs interaction has been compared between the nominal catenary and modified catenaries. In order to quantify the difference of the dynamic behaviour between these catenaries, the absolute value of the difference has been assessed along the section.

In the case of a section composed of 63 meter long spans, the three modified supports are located between the position $x=2600 \mathrm{~m}$ and $x=2800 \mathrm{~m}$ and are indicated by bold vertical dotted lines in figure 3 . Hereafter, these figures show the evolution of contact force of both leading and trailing pantographs on the nominal catenary and a modified one with these specific characteristics:

$$
\begin{aligned}
& Z_{x=2631 \mathrm{~m}}=Z_{\text {nominal }}+9 \mathrm{~cm} \\
& Z_{x=2694 \mathrm{~m}}=Z_{\text {nominal }}+0 \mathrm{~cm} \\
& Z_{x=2757 \mathrm{~m}}=Z_{\text {nominal }}-9 \mathrm{~cm}
\end{aligned}
$$



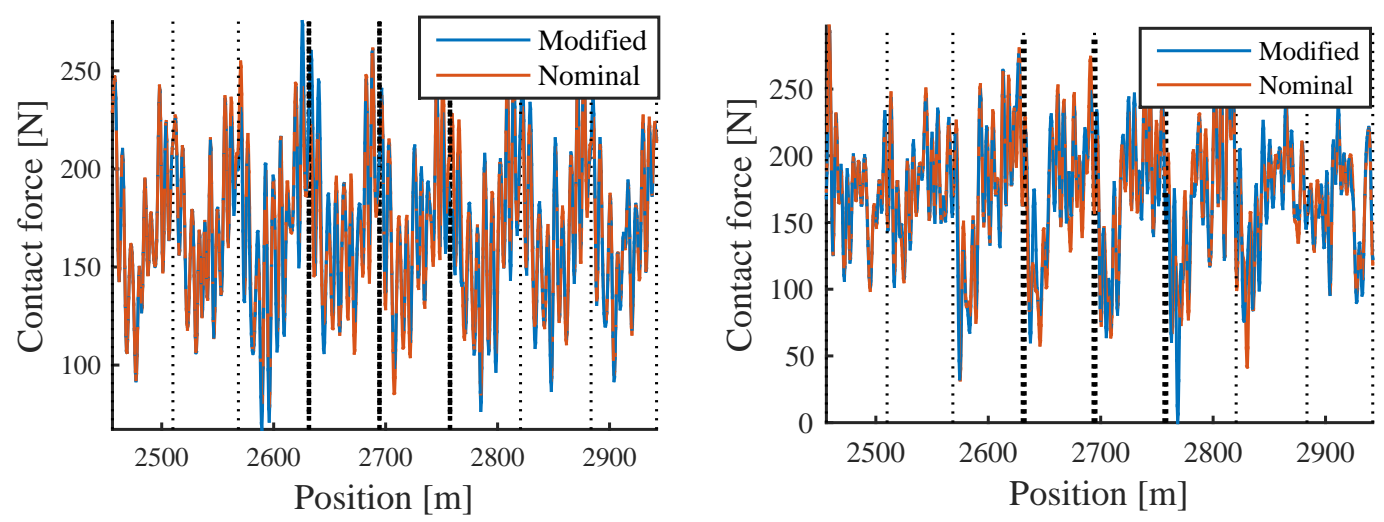

Figure 3: Contact force of leading (left) and trailing (right) pantographs for a nominal catenary (blue) and a catenary with three consecutive modification of $\boldsymbol{H}_{M W, M a s t}$

Visually, contact force of leading pantograph is modified between the supports changed and a bit further. Regarding trailing pantograph, the phenomenon is the same. Magnitude of the phenomenon seems to be higher than for the first pantograph.

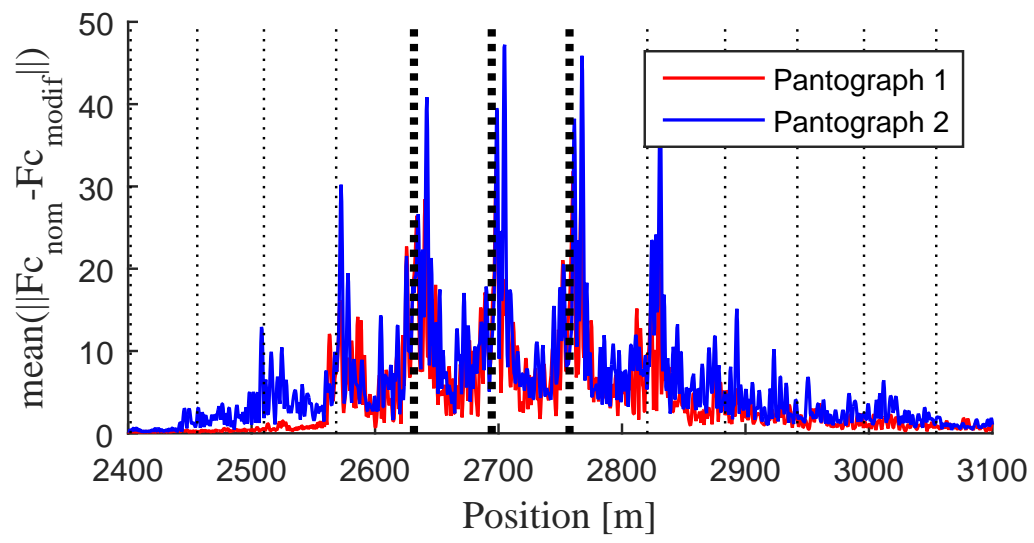

Figure 4: Absolute difference of contact force between the nominal and the modified catenary averaged over several simulations

Thousands of simulations have been carried out changing $\boldsymbol{H}_{M W, M a s t}$ arbitrary in a grid of $\pm 15 \mathrm{~cm}$. The average of the absolute value of the difference was computed in order to smooth local particular phenomena. Figure 4 shows the result for both pantographs.

As written previously, the influence of a few consecutive tweaked supports on the contact force is mainly and logically located between the changed supports. Over the previous span, the absolute difference increases. Similarly, this value decreases over the following spans. Finally, visually and mathematically, the influence of the vertical position of a support on the dynamic behaviour of the contact force is mainly located 
between the tweaked supports plus the four surrounding spans (two before and two after) and vanishes with distance.

\section{Selected criteria}

Two types of criteria are defined: the geometric and dynamic ones. Geometry criteria are deduced from the contact wire height and supposed to be measurable using existing vehicles. The basic objectives that are used in maintenance policy are limits of contact wire height $H_{C W}$ and limits of slope between two consecutive masts (i.e. along a span), $\Delta H_{C W, \text { Span }}$ [13]. Dynamic criteria are used to qualify the current collection quality. Only one mechanical criterion is commonly used for certification [14], namely the coefficient of variation of the $20 \mathrm{~Hz}$-filtered contact force which is defined as its standard deviation divided by its mean, $\left(\sigma / F_{m}\right)_{20 H z}$. In addition, the uplift at steady arms $U$ plift is also controlled for security purposes.

While $\left(\sigma / F_{m}\right)_{20 H z}$ is a scalar value for a given simulation, $H_{C W}$ and $\Delta H_{C W, \text { Span }}$ are vectors. As only scalars are possible for Sobol analysis, these dimensions are converted to scalars, taking for example their maxima or their standard deviation. Thus, $H_{C W}$ is observed as $\max \left(H_{C W}\right)$ and $\sigma\left(H_{C W}\right)$ which could give different information. For a correspondence with maintenance guidelines, threshold overruns are also observed as criteria, which will be denoted, for example with the contact wire height, $H_{C W}>5.12 m$.

In addition to these classical dimensions, several other that are believed to be relevant [4] are introduced. Following dimensions are thus observed:

- the difference of span slope at one mast: $\Delta^{2} H_{C W, \text { Span }}$

- the sag inside a span: $S a g$

- the slope between the steady arm and the first dropper and between the last dropper of a span and the steady arm: $\Delta H_{C W, D r o p}$

- the difference of dropper slope at mast: $\Delta^{2} H_{C W, D r o p, M a s t}$

- the difference of dropper slope at droppers before and after masts: $\Delta^{2} H_{C W, D r o p, D r o p}$

- Electrical "Non-Quality" criterion used in France [14] adapted to a mechanical criterion by setting a threshold of $40 \mathrm{~N}$ under which electrical arcs are supposed to exist $N Q$. An arc is taken into account if its time is longer than $5 \mathrm{~ms}$.

- Moving $\sigma / F_{m}$, the coefficient of variation of the contact force computed over $50 \mathrm{~m}$ along the catenary. It has been shown in [7] that the common criterion $\sigma / F_{m}$ might be too smoothed when averaged over the whole catenary. This new criterion is thus a mix between local and global criteria. 
Finally, all dynamic criteria are also computed for a $70 \mathrm{~Hz}$-filtered contact force as it is assumed that a significant amount of information is lost if $20 \mathrm{~Hz}$-filtered. OSCAR, the simulation tool used here, is only validated until $20 \mathrm{~Hz}$ by the standards [15] but results are reliable until the frequency of the first bending mode of the pantograph's bow, which is $100 \mathrm{~Hz}$ here. Table 2 summarizes all the selected criteria.

\section{Method}

Global sensitivity analysis using Sobol indices is based on the decomposition of the variance. The model is viewed as a black-box represented as a function $\boldsymbol{Y}=f(\boldsymbol{X})$ where $\boldsymbol{X}$ is the input random vector, $\boldsymbol{X}=\left(T_{M W}, T_{C W}, \boldsymbol{L}_{\text {drop }}, \boldsymbol{H}_{\boldsymbol{M W}, \boldsymbol{M a s t}}\right)$ and $\boldsymbol{Y}$ an univariate output. Sobol indices are computed separately for each criteria defined in section 3 .

First order Sobol indices $S_{1, i}$ and total-effect indices $S_{T, i}$ are defined by [16, 17]

$$
\begin{aligned}
S_{1, i} & =\frac{\operatorname{Var}_{X_{i}}\left(E_{X, \sim i}\left(Y \mid X_{i}\right)\right)}{\operatorname{Var}(Y)}, \\
S_{T, i} & =\frac{E_{X_{i}}\left(\operatorname{Var}_{X, \sim i}\left(Y \mid X_{i}\right)\right)}{\operatorname{Var}(Y)},
\end{aligned}
$$

where $\operatorname{Var}$ is the variance function, $E$ the expectation and $X_{\sim i}$ indicates the set of all input variables except $X_{i}$.

These indices cannot be directly computed but estimators exist to approximate them. Several estimators have been developed mainly by Sobol [16] and Jansen [18]. A comparison of two first order indices has been conducted by Janon [19] which led to the choice of Janon's estimator; the comparison for total effect indices is made by Satelli [20] which led to the choice of Jansen's estimator. They are defined as

$$
\begin{aligned}
S_{1, i}= & \frac{\frac{1}{N} \sum_{j=1}^{N} f(B)_{j} f\left(A_{B}^{(i)}\right)_{j}-\left(\frac{1}{N} \sum_{j=1}^{N} \frac{f(B)_{j}+f\left(A_{B}^{(i)}\right)_{j}}{2}\right)^{2}}{\frac{1}{N} \sum_{j=1}^{N} \frac{f(B)_{j}^{2}+f\left(A_{B}^{(i)}\right)_{j}^{2}}{2}-\left(\frac{1}{N} \sum_{j=1}^{N} \frac{f(B)_{j}+f\left(A_{B}^{(i)}\right)_{j}}{2}\right)^{2}}, \\
S_{T, i}= & \frac{\frac{1}{2 N} \sum_{j=1}^{N}\left(f(A)_{j}-f\left(A_{B}^{(i)}\right)_{j}\right)^{2}}{\frac{1}{N} \sum_{j=1}^{N} f(A)_{j}^{2}-\left(\frac{1}{N} \sum_{j=1}^{N} f(A)_{j}\right)^{2}} .
\end{aligned}
$$

where $B$ and $A$ are two samples of the same random vector $\boldsymbol{X}$ of size $N$ and $A_{B}^{(i)}$ is the sample $A$ with the $i^{\text {th }}$ component taken from sample $B$.

The main condition to apply the method is to have independent inputs, which is not the case for the different heights $\boldsymbol{H}_{M W, \text { Mast }}$. In that case, the solution of grouping correlated inputs together as proposed by Jacques [21], works well. Moreover, it is more interesting to have the impact of the size $\boldsymbol{H}_{M W, \text { Mast }}$ in general than for each 
span separately. This is also the case of all dropper lengths $\boldsymbol{L}_{d r o p}$, which are thus also grouped. Besides, reducing the number of group of inputs increases the convergence speed.

The sampling strategy chosen is the simple Monte-Carlo sampling. The convergence of the indicator can thus be well defined thanks to the bootstrap method described by Archer [22] or Yang [23]. The principle is to generate a sample of size $N$ with replacement of the set of output, which is also of size $N$. The Sobol indices can thus be computed from this sub-sample. Repeating the process $B=1000$ times allows to define $95 \%$ confidence intervals from these B values of Sobol indices. Gradually increasing $\mathrm{N}$ leads to the graph of convergence displayed in figure 5. The computation has been stopped at $N=1000$, which means 6000 dynamic simulations, after 3 weeks of computation.

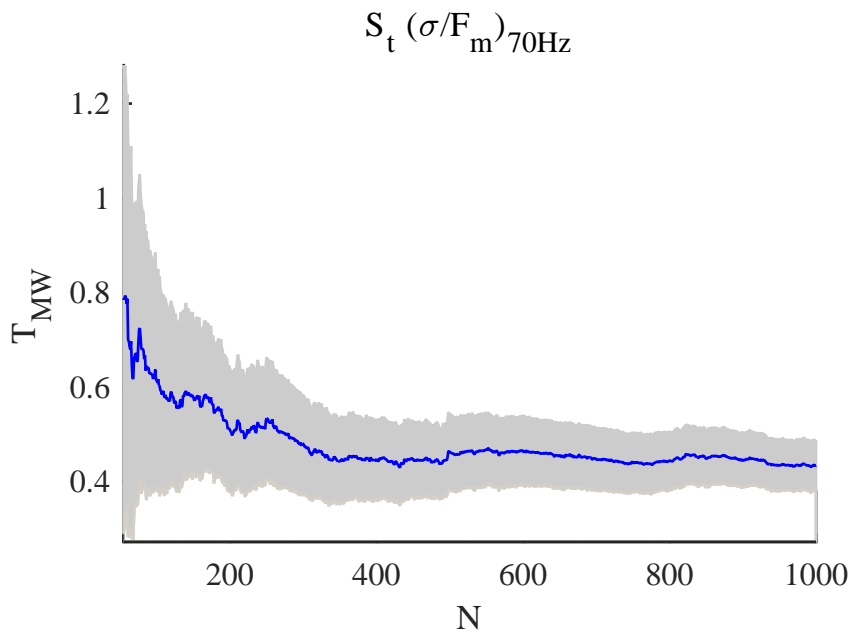

Figure 5: Convergence of the total Sobol indice of the parameter $T_{M W}$ on the criterion $\left(\sigma / F_{m}\right)_{70 H z}$

\section{Results}

Figure 6 shows the first order and total Sobol indices of $\left(\text { Moving } \sigma / F_{m}\right)_{70 H z}$ in a pie chart. To be able to know if the variation of the criterion is negligible, the mean value and standard deviation of the criterion are given. The sum of all first order indices hardly reaches more than a half for dynamic criteria, which means that a significant part of the criteria variation is due to combined effect of several input parameters. This result justifies entirely the use of a global sensitivity analysis instead of a local one. The most interesting part for maintenance application is thus the total effect Sobol indices. 

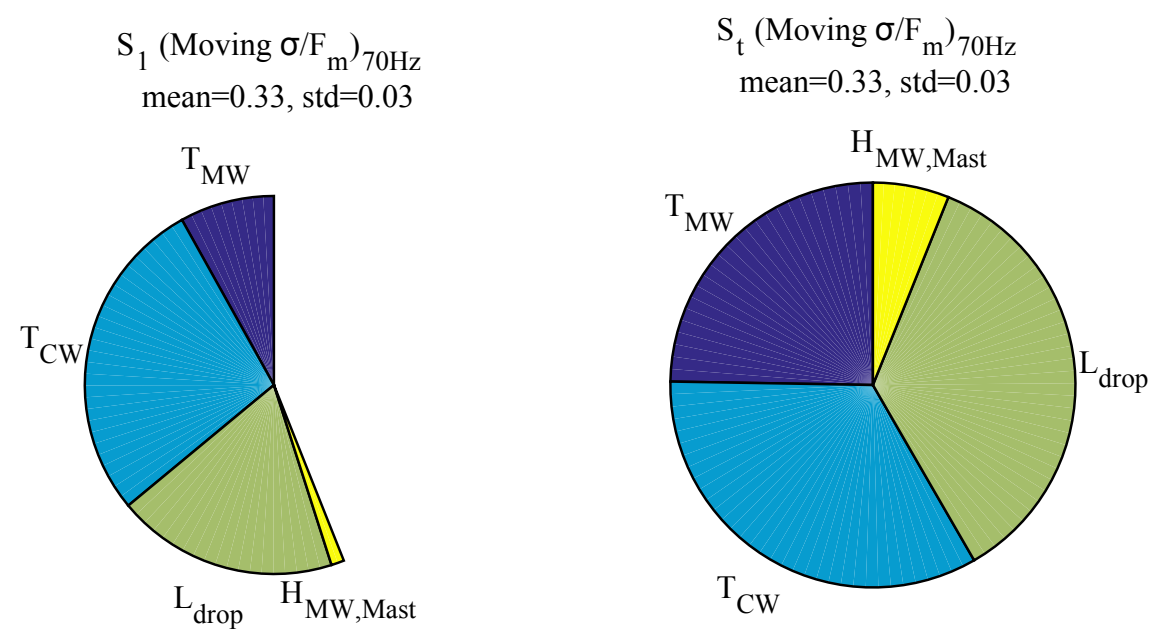

Figure 6: Sobol first order (left) and total (right) indices for $\left(M o v i n g ~ \sigma / F_{m}\right)_{70 H z}$

Figure 7 compares total effect indices for $\max \left(\Delta^{2} H_{C W, S p a n}\right)$ and $\Delta H_{C W, \text { Span }}>$ $2 \mathrm{~cm}$. In both cases, $\boldsymbol{H}_{\boldsymbol{M W}, \boldsymbol{M a s t}}$ has the main impact and the only other non-negligible parameter is $\boldsymbol{L}_{\text {drop }}$. Results are similar and information graphically given by these criteria can be redundant. The same conclusions are made when comparing them with $\operatorname{std}\left(\Delta^{2} H_{C W, \text { Span }}\right)$. It is thus not necessary to display all of them and only max will be shown.
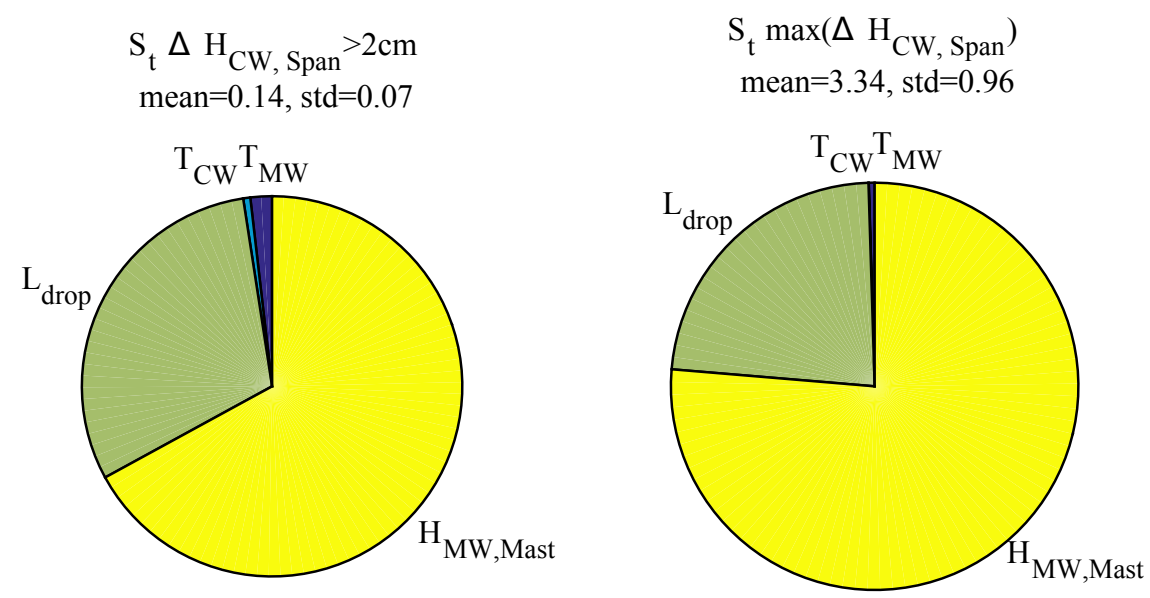

Figure 7: Sobol total indices for $\Delta H_{C W, \text { Span }}>2 \mathrm{~cm}$ (left) and $\max \left(\Delta^{2} H_{C W, \text { Span }}\right)$ (right)

Figure 8 shows three geometry criteria. The first, $\max \left(\Delta^{2} H_{C W, D r o p, D r o p}\right)$ which concerns local variations is twice as sensitive to $\boldsymbol{L}_{\boldsymbol{d r o p}}$ as $T_{C W}$ and $\boldsymbol{H}_{\boldsymbol{M W}, \boldsymbol{M a s t}}$. The second, $\max \left(\Delta^{2} H_{C W, S p a n}\right)$ which concern variations at the scale of the span, is mainly sensitive to $\boldsymbol{H}_{\boldsymbol{M} \boldsymbol{W}, \text { Mast }}$. The third, $\max (\mathrm{Sag})$ was introduced because it is 
known to be strongly impacted by variations of $T_{M W}$, which is confirmed by these results. Consequently, a combination of these criteria might well represent the variations of all input parameters except $T_{C W}$.

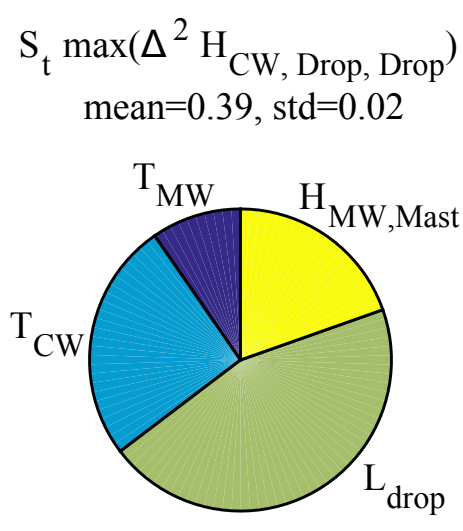

$$
\begin{gathered}
\mathrm{S}_{\mathrm{t}} \max \left(\Delta^{2} \mathrm{H}_{\mathrm{CW}, \text { Span }}\right) \\
\text { mean }=5.00, \mathrm{std}=1.50
\end{gathered}
$$

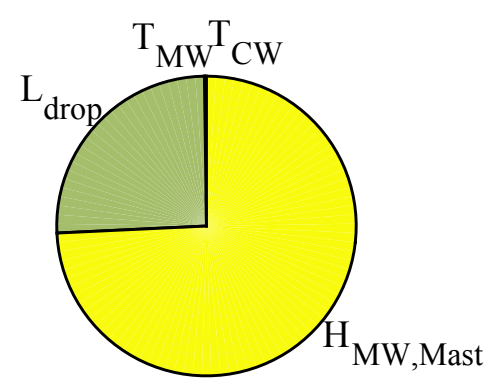

$$
\mathrm{S}_{\mathrm{t}} \max (\mathrm{Sag})
$$

mean $=7.24 \mathrm{e}-03$, std $=1.96 \mathrm{e}-03$

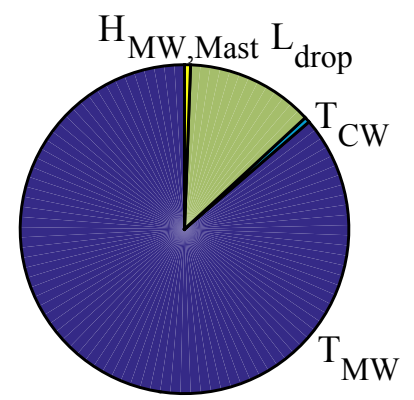

Figure 8: Sobol total indices for 3 geometry criteria

Figure 9 shows the resulting total Sobol indices for two different filtering frequencies of the contact force. The variations of the criterion $\mathrm{NQ}$ are higher for $70 \mathrm{~Hz}$ filtering than for a $20 \mathrm{~Hz}$ filtering. This observation is the same for all dynamic criteria and shows that the energy of the contact force between $20 \mathrm{~Hz}$ and $50 \mathrm{~Hz}$ is non negligible. To be more sensitive to input parameters, the higher frequency will be kept.
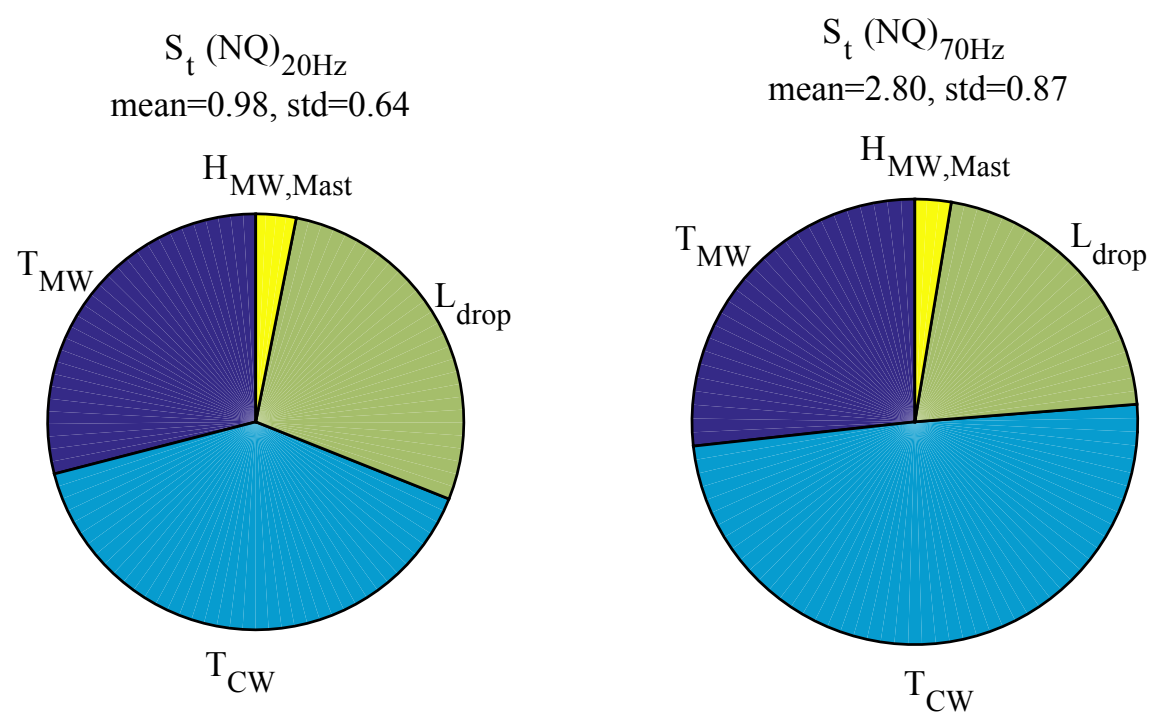

Figure 9: Sobol total indices for a dynamic criterion based on $20 \mathrm{~Hz}$ (left) and $70 \mathrm{~Hz}$ (right) filtered contact force

Figure 10 shows two dynamic criteria. The first, $\left(\sigma / F_{m}\right)_{70 H z}$, is global since it is 
the average coefficient of variation of contact force along the whole section. $T_{C W}$ is clearly the dominant parameter for more than the half and $T_{M W}$ and $\boldsymbol{L}_{\boldsymbol{d r o p}}$ share the rest. The second criterion, $\left(F_{\min }\right)_{70 \mathrm{~Hz}}$, is local since the minimum value happen only in one particular point. In that case, the sensitivity is equally divided between $T_{C W}$, $T_{M W}$ and $\boldsymbol{L}_{\text {drop }}$. In any case, $\boldsymbol{H}_{\boldsymbol{M W}, \text { Mast }}$ do not represent a significant part of the source of variability of dynamic criteria.
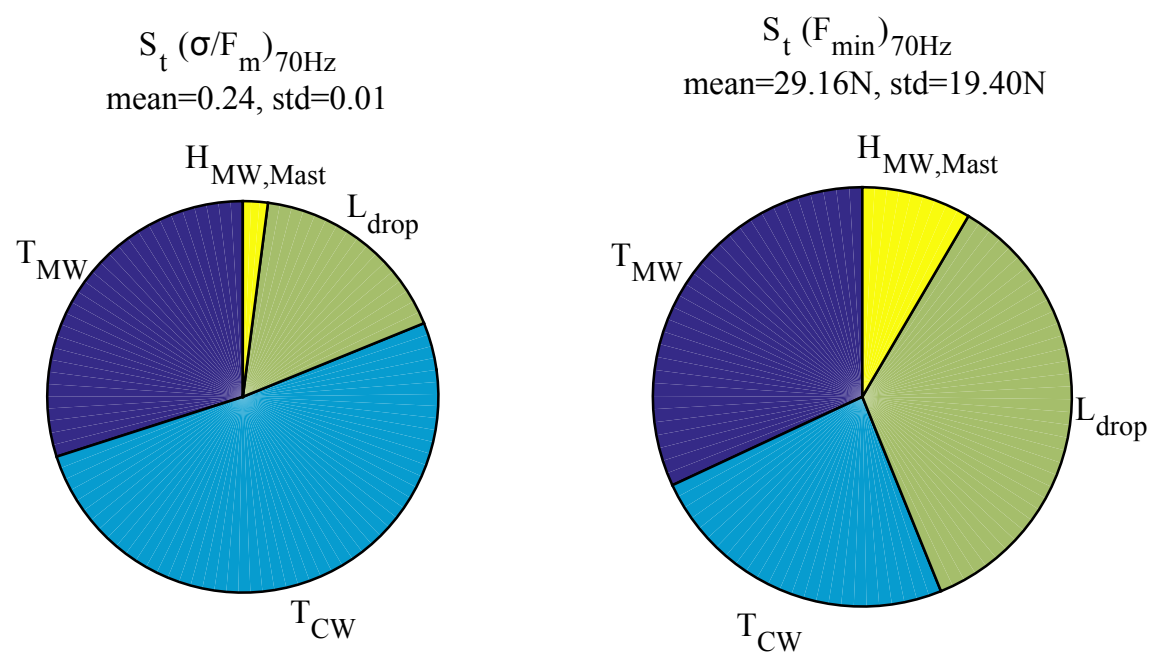

Figure 10: Sobol total indices for 2 dynamic criteria

All these results show that the correlation between geometric and dynamic criteria is light, since none of geometry criteria is mainly sensitive to $T_{C W}$, which has a high impact on dynamic criteria. Nevertheless, a non-negligible part of dynamic criteria variation is induced by $T_{M W}$ and $\boldsymbol{L}_{d r o p}$, approximately two third for local dynamic criteria.

\section{Conclusions}

All the variabilities of the catenary have been quantified and taken into account. The global sensitivity analysis was necessary because the combined effects of different parameters are non negligible. The study has shown that existing geometric criteria are poorly linked with the dynamic behaviour of the pantograph-catenary system. For maintenance, $\boldsymbol{L}_{\text {drop }}$ is not a parameter to control because the existing variations are not supposed to change in time. It is thus a design problem. The only parameter that is possible to observe from geometry measurement is thus $T_{M W}$, which is strongly correlated with the $S a g$ as shown in figure 11.

The only way to link maintenance policy with current collection quality is thus to define dynamic criteria. But if an issue in one dynamic criterion is observed, the correction to carry on is not an evidence. For example, if the global dynamic criterion 


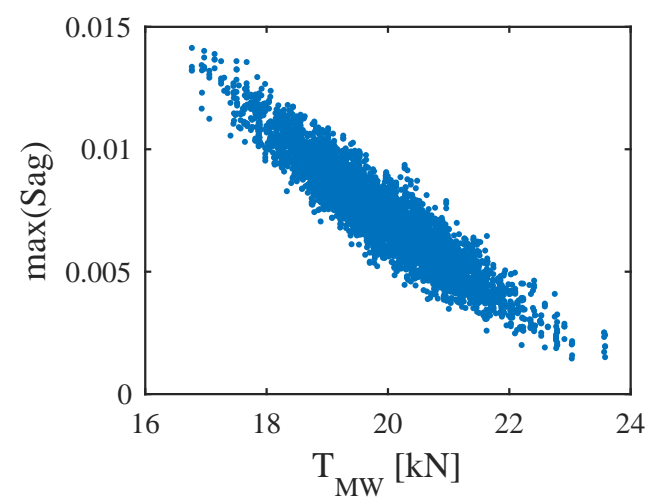

Figure 11: $\max (\operatorname{Sag})$ against the messenger wire tension for the 6000 simulations

like $\left(\sigma / F_{m}\right)_{70 H z}$ is observed against different input parameters as shown in figure 12, it is clear that $\left(\sigma / F_{m}\right)_{70 H z}$ depends lightly on $T_{C W}$ and $T_{M W}$ but a strong correlation can be observed with the combination $T_{C W}+T_{M W}$. The combined effect of $T_{C W}$ and $T_{M W}$ is indeed not clearly understood and needs further studies.
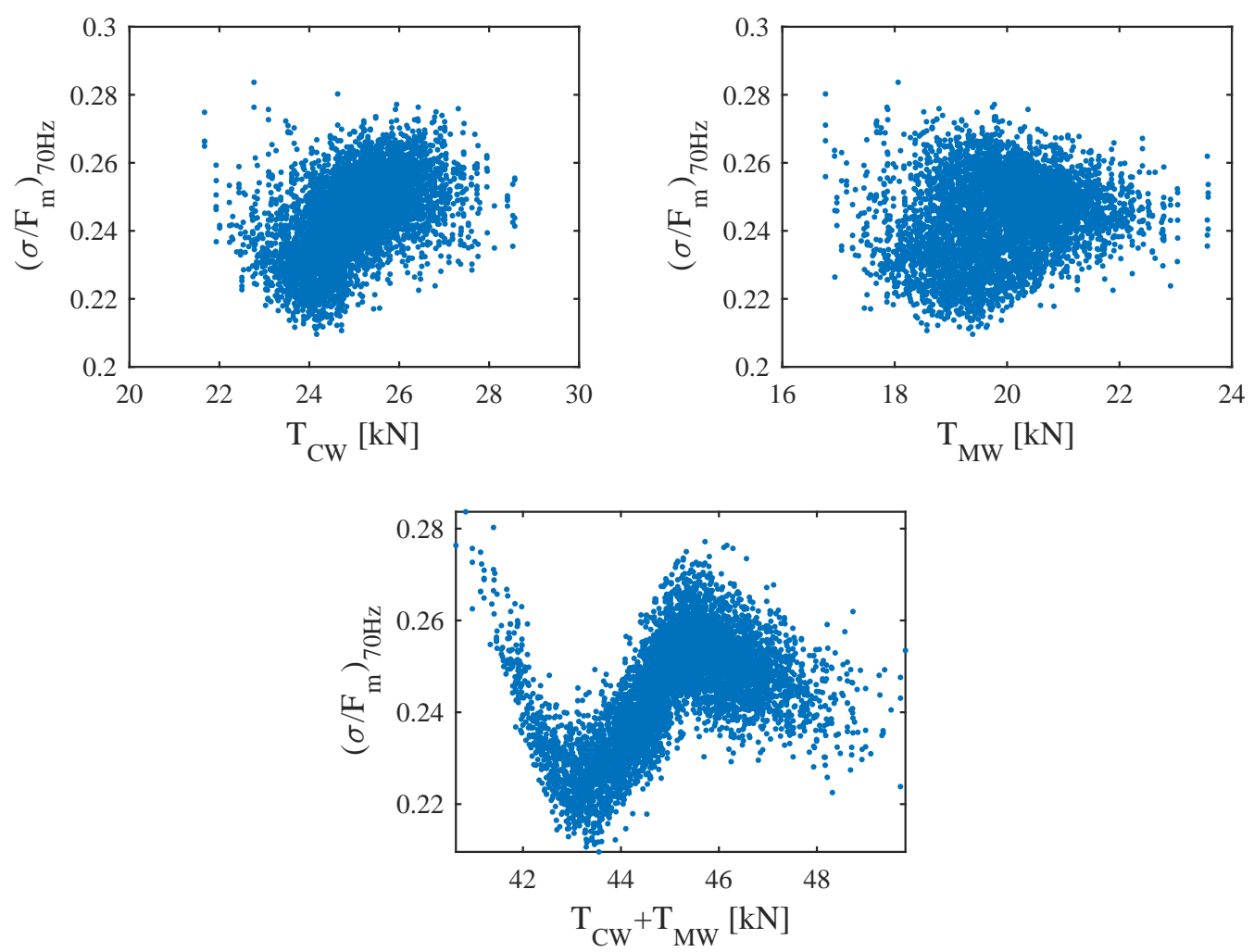

Figure 12: $\left(\sigma / F_{m}\right)_{70 H z}$ against $T_{C W}$ (left), $T_{M W}$ (right) and $T_{C W}+T_{M W}$ (bottom) 


\section{References}

[1] S. Bruni, J. Ambrosio, A. Carnicero, Y.H. Cho, L. Finner, M. Ikeda, S.Y. Kwon, J.P. Massat, S. Stichel, M. Tur, W. Zhang, "The results of the pantograph - catenary interaction benchmark", Vehicle System Dynamics, 53(2): 1-24, 2014, ISSN 0042-3114, URL http://www.tandfonline.com/doi/ abs/10.1080/00423114.2014.953183.

[2] T.J. Park, C.S. Han, J.H. Jang, "Dynamic sensitivity analysis for the pantograph of a high-speed rail vehicle", Journal of Sound and Vibration, 266(2): 235-260, 2003, ISBN 8231400524, ISSN 0022460X.

[3] J. Pombo, J. Ambrósio, "Influence of pantograph suspension characteristics on the contact quality with the catenary for high speed trains", Computers and Structures, 110-111: 32-42, 2012, ISBN 0045-7949, ISSN 00457949, URL http://dx.doi.org/10.1016/j.compstruc.2012.06.005.

[4] M. Aboshi, M. Tsunemoto, "Installation Guidelines for Shinkansen High Speed Overhead Contact Lines", QR of RTRI, 52(4): 230-236, 2011.

[5] J.W. Kim, H.C. Chae, B.S. Park, S.Y. Lee, C.S. Han, J.H. Jang, "State sensitivity analysis of the pantograph system for a high-speed rail vehicle considering span length and static uplift force", Journal of Sound and Vibration, 303(3-5): 405427, 2007, ISBN 8231400524, ISSN 0022460X.

[6] N. Zhou, W. Zhang, "Investigation on dynamic performance and parameter optimization design of pantograph and catenary system", Finite Elements in Analysis and Design, 47(3): 288-295, 2011, ISSN 0168874X, URL http: //dx.doi.org/10.1016/j.finel.2010.10.008.

[7] O. Vo Van, J.p. Massat, C. Laurent, E. Balmes, "Introduction of variability into pantograph- catenary dynamic simulations", Vehicle System Dynamics, 52(10): 1254-1269, 2014, ISSN 0042-3114, URL http: / / www.tandfonline. $\mathrm{com} / \mathrm{doi} / \mathrm{abs} / 10.1080 / 00423114.2014 .922199$.

[8] O. Vo Van, E. Balmes, J.p. Massat, "Statistical identification of geometric parameters for high speed train catenary", in International Conference on Noise and Vibration, pages 2-11. Leuven, 2014.

[9] E.T. Jaynes, "Information theory and statistical mechanics. II", Physical Review, 108(2): 171-190, 1957, ISBN 1536-6065, ISSN 0031899X.

[10] K. Conrad, "Probability distributions and maximum entropy", Entropy, pages 127, 2004, URL http://www. math.uconn.edu/ kconrad/blurbs/ analysis/entropypost.pdf. 
[11] R.G. Gallager, "Gaussian random vectors and processes", in Stochastic Processes, Theory for Applications, pages 101-160. Cambridge University Press, Cambridge, 2014, ISBN 9781107039759.

[12] G. Perrin, C. Soize, D. Duhamel, C. Funfschilling, G. Perrin, C. Soize, D. Duhamel, C.F.A. Posteri, "A Posteriori error and optimal reduced basis for stochastic processes defined by a finite set of realizations", SIAM/ASA Journal on Uncertainty Quantification, 2: 745-762, 2014.

[13] SNCF, "Collection of standards for overhead contact lines $\mathrm{AC} / 25 \mathrm{kV} / 50 \mathrm{~Hz}$ ", Internal Report - IN 1797, 2006.

[14] AFNOR, "Railway application - Current collection systems - Requirements for and validation of measurements of the dynamic interaction between pantograph and overhead contact line", NF EN50317, 2002.

[15] AFNOR, "Railway application - Current collection systems - Validation of simulation of the dynamic interaction between pantograph and overhead contact line", NF EN50318, 2002.

[16] I.M. Sobol, "Global sensitivity indices for nonlinear mathematical models and their Monte Carlo estimates", Mathematics and Computers in Simulation, 55 (1-3): 271-280, 2001.

[17] T. Homma, A. Satelli, "Importance measures in global sensitivity analysis of nonlinear models", Reliability Engineering \& System Safety, 52(1): 1-17, 1996.

[18] M.J.W. Jansen, W.A.H. Rossing, R.A. Daamen, "Monte Carlo estimation of uncertainty contributions from several independent multivariate sources", in J. Grasman, G. van Straten (Editors), Predictability and Nonlinear Modelling in Natural Sciences and Economics, Chapter 4, pages 334-343. SPRINGERSCIENCE+BUSINESS MEDIA, BV., 1994, ISBN 978-94-010-4416-5.

[19] A. Janon, T. Klein, A. Lagnoux-Renaudie, M. Nodet, C. Prieur, "Asymptotic normality and efficiency of two Sobol index estimators ementine Prieur To cite this version :", ESAIM: Probability and Statistics, 18: 342-364, 2014.

[20] A. Saltelli, P. Annoni, I. Azzini, F. Campolongo, M. Ratto, S. Tarantola, "Variance based sensitivity analysis of model output . Design and estimator for the total sensitivity index", Computer Physics Communications, 181(2): 259-270, 2010, ISSN 0010-4655, URL http://dx.doi.org/10.1016/j.cpc. 2009.09 .018$.

[21] J. Jacques, C. Lavergne, N. Devictor, "Sensitivity analysis in presence of model uncertainty and correlated inputs", Reliability Engineering \& System Safety, 91 (10-11): 1126-1134, 2006. 
[22] G.E.B. Archer, A. Saltelli, I.M. Sobol, "Sensitivity measures, ANOVA-like techniques and the use of bootstrap", Journal of Statistical Computation and Simulation, 58(2): 99-120, 1997, URL http://www.tandfonline.com/doi/ citedby/10.1080/00949659708811825.

[23] J. Yang, "Environmental Modelling \& Software Convergence and uncertainty analyses in Monte-Carlo based sensitivity analysis", Environmental Modelling and Software, 26(4): 444-457, 2011, ISSN 1364-8152, URL http://dx . doi.org/10.1016/j.envsoft.2010.10.007.

\section{Annexe}

Table 2: Geometric and Dynamic criteria

\begin{tabular}{|c|c|}
\hline $\max \left(H_{C W}\right)$ & maximum of contact wire height \\
\hline $\max \left(\Delta H_{C W, \text { Span }}\right)$ & maximum of slope in a span \\
\hline $\max \left(\Delta^{2} H_{C W, \text { Span }}\right)$ & maximum of difference of span slope at a mast \\
\hline $\max (\operatorname{Sag})$ & maximum sag in a span \\
\hline $\max \left(\Delta H_{C W, D r o p}\right)$ & $\begin{array}{l}\text { maximum of slope between the steady arm and the first } \\
\text { dropper and between the last dropper of a span and the } \\
\text { steady arm }\end{array}$ \\
\hline $\max \left(\Delta^{2} H_{C W, \text { Drop }, \text { Mast }}\right)$ & maximum of difference of dropper slope at mast \\
\hline $\max \left(\Delta^{2} H_{C W, \text { Drop,Drop }}\right)$ & $\begin{array}{l}\text { maximum of difference of dropper slope at droppers be- } \\
\text { fore and after masts }\end{array}$ \\
\hline$\sigma\left(H_{C W}\right)$ & standard deviation of contact wire height \\
\hline$\sigma\left(\Delta H_{C W, \text { Span }}\right)$ & standard deviation of slope in a span \\
\hline $\begin{array}{c}\sigma\left(\Delta^{2} H_{C W, \text { Span }}\right) \\
\sigma(\text { Sag })\end{array}$ & $\begin{array}{l}\text { standard deviation of difference of span slope at a mast } \\
\text { standard deviation of sag in a span }\end{array}$ \\
\hline$\sigma\left(\Delta H_{C W, \text { Drop }}\right)$ & $\begin{array}{l}\text { standard deviation of slope between the steady arm and } \\
\text { the first dropper and between the last dropper of a span } \\
\text { and the steady arm }\end{array}$ \\
\hline$\sigma\left(\Delta^{2} H_{C W, \text { Drop }, \text { Mast }}\right)$ & standard deviation of difference of dropper slope at mast \\
\hline$\sigma\left(\Delta^{2} H_{C W, \text { Drop }, \text { Drop }}\right)$ & $\begin{array}{l}\text { standard deviation of difference of dropper slope at } \\
\text { droppers before and after masts }\end{array}$ \\
\hline$H_{C W}>5.12 m$ & Proportion of contact wire height over $5.12 \mathrm{~cm}$ \\
\hline$\Delta H_{C W, \text { Span }}>2 \mathrm{~cm}$ & Proportion of slope in a span over $2 \mathrm{~cm}$ \\
\hline$\Delta^{2} H_{C W, \text { Span }}>4 \mathrm{~cm}$ & $\begin{array}{l}\text { Proportion of difference of span slope at a mast over } \\
4 \mathrm{~cm}\end{array}$ \\
\hline$S a g>0.6 m m / m$ & Proportion of sag in a span over $0.6 \mathrm{~mm} / \mathrm{m}$ \\
\hline$\Delta H_{C W, \text { Drop }}>0.2 \mathrm{~cm}$ & $\begin{array}{l}\text { Proportion of slope between the steady arm and the first } \\
\text { dropper and between the last dropper of a span and the } \\
\text { steady arm over } 0.2 \mathrm{~cm}\end{array}$ \\
\hline$\Delta^{2} H_{C W, \text { Drop }, \text { Mast }}>0.2$ & $\begin{array}{l}\text { Proportion of difference of dropper slope at mast over } \\
0.2 \mathrm{~cm}\end{array}$ \\
\hline
\end{tabular}




\begin{tabular}{|c|c|}
\hline$\Delta^{2} H_{C W, \text { Drop }, \text { Drop }}>0.2$ & $\begin{array}{l}\text { Proportion of of difference of dropper slope at droppers } \\
\text { before and after masts over } 0.2 \mathrm{~cm}\end{array}$ \\
\hline $\begin{array}{c}\left(F_{\min }\right)_{20 \mathrm{~Hz}} \\
\left(F_{\max }\right)_{20 \mathrm{~Hz}} \\
\left(\sigma / F_{m}\right)_{20 \mathrm{~Hz}} \\
\text { Moving }\left(\sigma / F_{m}\right)_{20 \mathrm{~Hz}} \\
(N Q)_{20 \mathrm{~Hz}} \\
\left(F_{\min }\right)_{70 H z} \\
\left(F_{\max }\right)_{70 H z} \\
\left(\sigma / F_{m}\right)_{70 H z} \\
\text { Moving }\left(\sigma / F_{m}\right)_{70 H z}\end{array}$ & $\begin{array}{l}\text { minimum } 20 \mathrm{~Hz} \text {-filtered contact force } \\
\text { maximum } 20 \mathrm{~Hz} \text {-filtered contact force } \\
\text { coefficient of variation of } 20 \mathrm{~Hz} \text {-filtered contact force } \\
\text { maximum of coefficient of variation of } 20 \mathrm{~Hz} \text {-filtered } \\
\text { contact force computed over } 50 \mathrm{~m} \text { along the catenary } \\
\text { proportion of time during which } 20 \mathrm{~Hz} \text {-filtered contact } \\
\text { force is under } 40 \mathrm{~N} \text {, if the period is longer than } 5 \mathrm{~ms} \\
\text { minimum } 70 \mathrm{~Hz} \text {-filtered contact force } \\
\text { maximum } 70 \mathrm{~Hz} \text {-filtered contact force } \\
\text { coefficient of variation of } 70 \mathrm{~Hz} \text {-filtered contact force } \\
\text { maximum of coefficient of variation of } 70 \mathrm{~Hz} \text {-filtered } \\
\text { contact force computed over } 50 \mathrm{~m} \text { along the catenary } \\
\text { proportion of time during which } 70 \mathrm{~Hz} \text {-filtered contact } \\
\text { force is under } 40 \mathrm{~N} \text {, if the period is longer than } 5 \mathrm{~ms} \\
\text { maximum uplift at steady arm }\end{array}$ \\
\hline
\end{tabular}

